\title{
ANALYSIS OF EFFECT OF MOMENTUM ON THE BEHAVIOR OF RC BEAMS UNDER LOW VELOCITY IMPACT LOADING
}

\author{
YONG JAE YU \& JAE-YEOL CHO \\ Department of Civil and Environmental Engineering, Seoul National University, South Korea
}

\begin{abstract}
Recently, the demand for structural safety under impact loading has been increased because the risk of exposure to the infrastructure to impact loading increases. The behavior of the structures under impact loading is a very complex phenomenon. For this reason, it is required to develop a rational method to estimate the impact resistance of structures. Some researchers have suggested performance based design method to do this. They conducted drop weight impact test and proposed empirical equations for evaluating the impact resistance. However, these equations were derived from small impact energy range. In addition, these equations did not consider the effect of the momentum of drop weight and only reflected the impact energy of drop weight. There are various combinations of mass and impact velocity of drop weight having the same impact energy. Thus, it is also necessary to consider the momentum of the drop weight. In this study, the effect of the momentum of drop weight is assessed through finite element analysis using LS-DYNA program. From this analysis, it was confirmed that the behaviors of $\mathrm{RC}$ beams such as maximum deflection and failure mode are related to the combination. These results imply that the design of concrete structures subjected to impact loading should consider the momentum, that is, a combination of mass and impact velocity.

Keywords: momentum, finite element analysis, drop weight impact test.
\end{abstract}

\section{INTRODUCTION}

Nowadays, infrastructures are often damaged by the impact loading, thus it is important to ensure the safety of the infrastructures under impact loading. Especially, low velocity impact loading such as rock fall, vehicle and ship collision occurs in the infrastructure in the civil engineering field. Thus, it is essential to evaluate the structures under low velocity impact loading to ensure the safety of the infrastructures. However, it is difficult to predict the behavior of the structures subjected to the impact loading. Because the behavior of the structures under impact loading is different from that of under static loading and is very complicated. To overcome this, some researchers have suggested empirical equations by performing the drop weight impact test [1]-[4]. Using these equations, the static flexural capacity is determined according to the required performance, maximum or residual deflection, and the cross section or placement of the rebar can be relatively easily determined. In addition, in case of existing $\mathrm{RC}$ beams, the maximum or residual deflection can be predicted under specific impact loading.

However, these equations only consider the impact energy, which is equal to the kinetic energy of drop weight. The impact energy is composed of mass and impact velocity of drop weight, so there is a various combination of mass and impact velocity with same impact energy. Therefore, considering only the impact energy is not enough to accurately predict the behavior of the structure, and further consideration of momentum is needed.

In this study, the effect of the combination was validated through the finite element analysis of RC beam using LS-DYNA program. In this analysis, a drop weight impact test using rigid masses to simulate a low velocity impact loading. And then, 3 cases of impact energy, 13 cases of the momentum of drop weight with same impact energy and the same shape of the drop weight was used to estimate the effect of the momentum of drop weight. 
Based on the results of this analysis, it was confirmed that the behavior of $\mathrm{RC}$ beams such as maximum deflection and failure mode depends on the momentum of drop weight. Therefore, it is essential to consider the effect of momentum in the previous empirical equations to evaluate the structures under the impact loading more accurate.

\section{PREVIOUS RESEARCH}

\subsection{Empirical equations}

Tachibana et al. [2] suggested empirical equations to determine the required static flexural load carrying capacity of RC beams for resisting a given impact energy. Kishi et al. [3] also proposed the empirical equations for the same purpose. These empirical equations were suggested for the maximum and residual deflection. In this paper, the maximum deflection is only considered because the maximum deflection is directly related to the failure of the RC beam.

2.1.1 Equations of Tachibana et al.

Tachibana et al. [2] demonstrated the impulse resulting from the impact loading was proportional to the momentum of the impacting mass. Then, the maximum deflection was inversely proportional to the mean impact force $\mathrm{P}_{\mathrm{m}}$ and the maximum deflection was a proportional relation to the value of the impact energy divided by the mean impact force $\mathrm{E} / \mathrm{P}_{\mathrm{m}}$ as eqn (1).

$$
\delta_{\max }=0.711 \frac{\mathrm{E}}{\mathrm{P}_{\mathrm{m}}}
$$

In addition, the mean impact force $\mathrm{P}_{\mathrm{m}}$ is proportional to the static flexural loading capacity $\mathrm{P}_{\mathrm{u}}$ as eqn (2).

$$
\mathrm{P}_{\mathrm{m}}=1.36 \mathrm{P}_{\mathrm{u}}
$$

From eqns (1) and (2), the following empirical equation was proposed.

$$
\delta_{\max }=0.522 \frac{\mathrm{E}}{\mathrm{P}_{\mathrm{u}}} .
$$

\subsubsection{Equation of Kishi and Mikami}

Kishi and Mikami [3] demonstrated the maximum defection $\delta_{\max }$ was almost proportional with respect to the input impact energy $\mathrm{E}$ as eqn (4) from the drop weight impact load tests. The $\alpha$ is the coefficient of maximum deflection and the unit of $\alpha$ is $1 / \mathrm{kN}$.

$$
\delta_{\max }=\alpha \mathrm{E} .
$$

Then, they also investigated the coefficient of the maximum deflection which can be empirically formulated with high correlation using the inverse of the static flexural load carrying capacity $\mathrm{P}_{\mathrm{u}}$ as eqn (5). 


$$
\alpha=\frac{0.63}{\mathrm{P}_{\mathrm{u}}} .
$$

From eqns (4) and (5), the following empirical equation was proposed.

$$
\delta_{\max }=0.63 \frac{\mathrm{E}}{\mathrm{P}_{\mathrm{u}}}
$$

2.1.3 Limitations of previous empirical equations

Previous empirical equations were proposed in the same form as eqn (4), and the coefficient of the maximum deflection is constant and this value differs according to the research. From the previous studies, it was confirmed that the maximum deflection was proportional to the input energy divided by static flexural capacity. However, these equations did not consider the effect of the momentum of drop weight. Based on the impulse-momentum theorem, the momentum change is equal to the impulse. Impulse is a product of the impact force and time, which is closely related to the time history of the impact force surcharged on the RC beams. Therefore, the momentum of the drop weight can have a great influence on the behavior of the $\mathrm{RC}$ beam and then, it is essential to investigate the effect of the momentum of drop weight.

\section{FINITE ELEMENT ANALYSES}

\subsection{Overview of finite element analysis}

Two types of RC beam were used in this analysis as shown in Fig. 1. A rectangular cross section beam was used and the section height was changed to investigate the effect of the static flexural capacity. These beams were designed to cause flexural failure under static state and conduct the experiment using the drop weight impact tester at Extreme Performance Testing Center of Seoul National University in the future.

The beam and frame were modeled as $3 \mathrm{~d}$ solid element and the longitudinal and shear rebar were modeled as beam element as shown in Fig. 2. The boundary conditions are set that the bottom of the support only allowing the rotation around the x-axis as well as experimenting. Contact between drop weight and beam, beam and frame were set using the keyword *CONTACT_AUTOMATIC provided in LS DYNA. Between concrete and rebar were assumed to be perfectly bond.
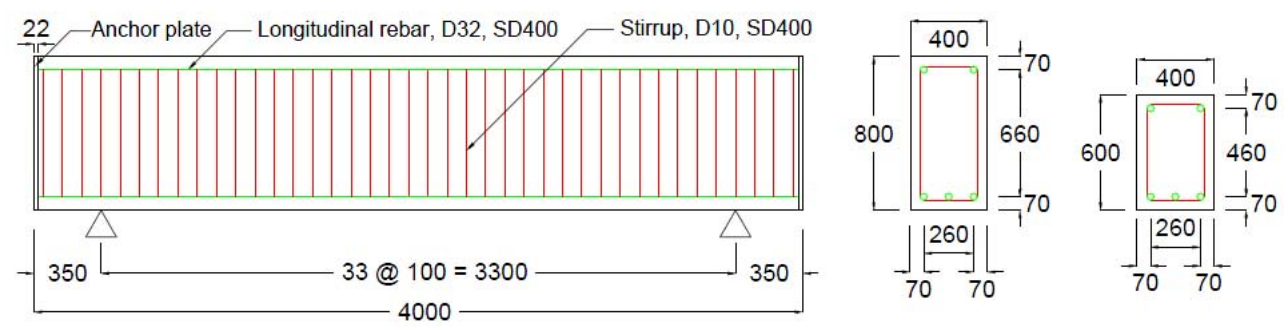

Figure 1: RC beam used in the FE analysis. 


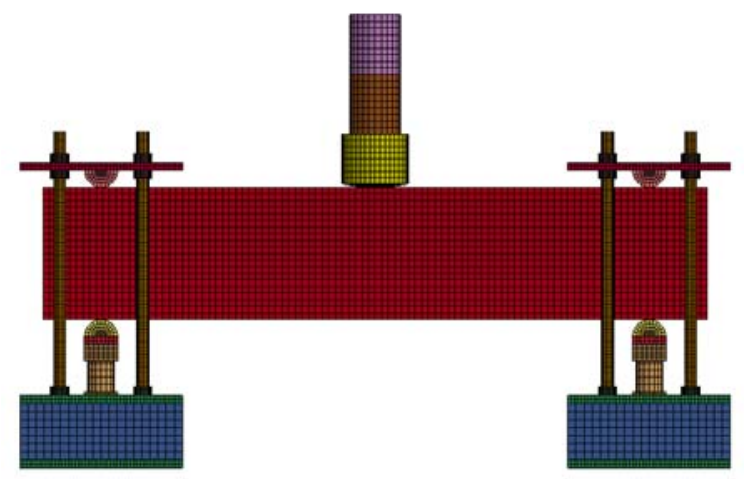

Figure 2: 3D modeling of RC beam.

\subsection{Material model}

MAT72R3 material model was used for concrete. This model is based on $\mathrm{K} \& \mathrm{C}$ model that is a three invariant model and define the three-failure surface, yield surface, limit surface and residual surface. After the loading, the stresses are elastic until the yield surface is reached. Then the yield surface hardens to the limit surface or softens to the residual surface. To use the MAT72R3, various parameter should be determined, which can be obtained from the experiment. However, there is no laboratory data, and thus the default value of LS DYNA and the value suggested by N. Marcovich et al. [5] are adapted for this analysis.

MAT24 material model was used for rebar. Bi-linear stress-strain curve was assumed and plastic hardening modulus was assumed as $1 \%$ of elastic modulus. Drop weight, support, and other parts were defined as a bi-linear model to consider the plastic behavior.

\subsection{Variables}

In this analysis, the static flexural capacity, impact energy and the momentum of drop weight were set as the variables. Especially, the static flexural capacity was determined by the cross section, and the momentum was determined by the combination of mass and impact velocity of drop weight. Two cases of static flexural capacity, 13 cases of mass and impact velocity of drop weight and 3 cases of impact energy were used as variables are shown in Table 1.

\section{ANALYSES RESULTS}

\subsection{Maximum deflection}

Maximum deflection at the mid-span was calculated from the FE analysis and the maximum deflection depends on the momentum as shown in Fig. 3. In Fig. 3, $E_{k}$ means that impact energy and $\mathrm{P}_{\text {static }}$ is equal to the static flexural capacity. In addition, it was confirmed that the maximum deflection differs according to the static flexural capacity. The momentum was highly related to the alpha, the coefficient of the maximum deflection in eqn (7), and the difference in the alpha is low. In addition, the alpha was confirmed to be variable for momentum as shown in Fig. 4. From these results, it can be seen that the momentum of drop weight has a great effect on the maximum deflection and the effect of the momentum should be considered in the previous empirical equation. 
Table 1: Details of variables of FE analysis.

\begin{tabular}{|c|c|c|c|c|c|}
\hline $\begin{array}{l}\text { Static flexural } \\
\text { capacity }(\mathrm{kN})\end{array}$ & $\begin{array}{c}\text { Impact } \\
\text { energy }(\mathrm{kJ})\end{array}$ & Case & $\begin{array}{l}\text { Mass } \\
\text { (ton) }\end{array}$ & $\begin{array}{c}\text { Impact } \\
\text { velocity }(\mathrm{m} / \mathrm{s})\end{array}$ & $\begin{array}{c}\text { Momentum } \\
\text { (ton-m/s) }\end{array}$ \\
\hline \multirow{17}{*}{554} & \multirow{13}{*}{15} & 1 & 9.00 & 1.83 & 16.43 \\
\hline & & 2 & 7.51 & 2.00 & 15.01 \\
\hline & & 3 & 6.00 & 2.24 & 13.41 \\
\hline & & 4 & 4.52 & 2.58 & 11.64 \\
\hline & & 5 & 4.03 & 2.73 & 10.99 \\
\hline & & 6 & 3.02 & 3.15 & 9.52 \\
\hline & & 7 & 2.53 & 3.45 & 8.71 \\
\hline & & 8 & 2.03 & 3.84 & 7.81 \\
\hline & & 9 & 1.49 & 4.49 & 6.68 \\
\hline & & 10 & 1.09 & 5.24 & 5.73 \\
\hline & & 11 & 0.70 & 6.55 & 4.58 \\
\hline & & 12 & 0.30 & 9.92 & 3.02 \\
\hline & & 13 & 0.10 & 17.32 & 1.73 \\
\hline & \multirow{13}{*}{30} & 1 & 9.00 & 2.58 & 22.23 \\
\hline & & 2 & 7.51 & 2.83 & 21.23 \\
\hline & & 3 & 6.00 & 3.16 & 18.97 \\
\hline & & 4 & 4.52 & 3.64 & 16.46 \\
\hline \multirow{22}{*}{785} & & 5 & 4.03 & 3.86 & 15.55 \\
\hline & & 6 & 3.02 & 4.46 & 13.47 \\
\hline & & 7 & 2.53 & 4.87 & 12.31 \\
\hline & & 8 & 2.03 & 5.43 & 11.05 \\
\hline & & 9 & 1.49 & 6.35 & 9.45 \\
\hline & & 10 & 1.09 & 7.41 & 8.10 \\
\hline & & 11 & 0.70 & 9.26 & 6.48 \\
\hline & & 12 & 0.30 & 14.04 & 4.27 \\
\hline & & 13 & 0.10 & 24.49 & 2.45 \\
\hline & \multirow{13}{*}{50} & 1 & 9.00 & 3.33 & 29.99 \\
\hline & & 2 & 7.51 & 3.65 & 27.41 \\
\hline & & 3 & 6.00 & 4.08 & 24.49 \\
\hline & & 4 & 4.52 & 4.70 & 21.25 \\
\hline & & 5 & 4.03 & 4.98 & 20.07 \\
\hline & & 6 & 3.02 & 5.75 & 17.39 \\
\hline & & 7 & 2.53 & 6.29 & 15.90 \\
\hline & & 8 & 2.03 & 7.01 & 14.26 \\
\hline & & 9 & 1.49 & 8.20 & 12.20 \\
\hline & & 10 & 1.09 & 9.56 & 10.46 \\
\hline & & 11 & 0.70 & 11.96 & 8.36 \\
\hline & & 12 & 0.30 & 18.12 & 5.52 \\
\hline & & 13 & 0.10 & 31.62 & 3.16 \\
\hline
\end{tabular}




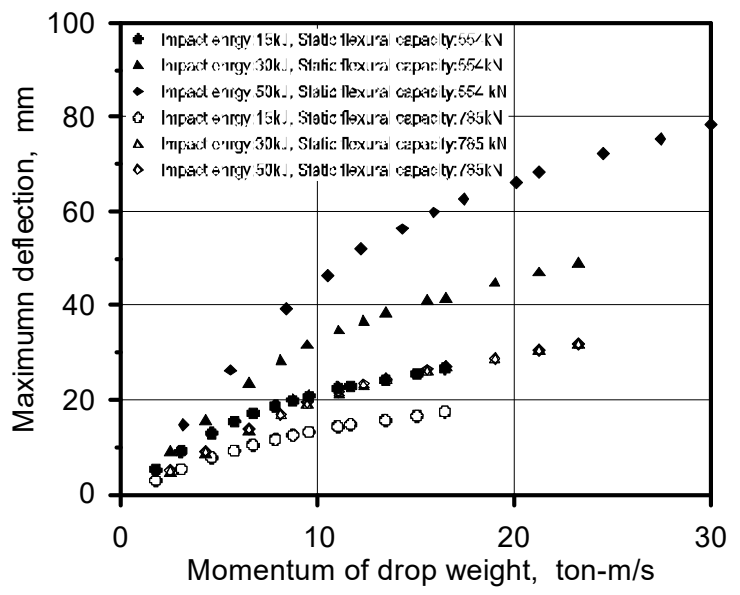

Figure 3: Maximum deflection for momentum.

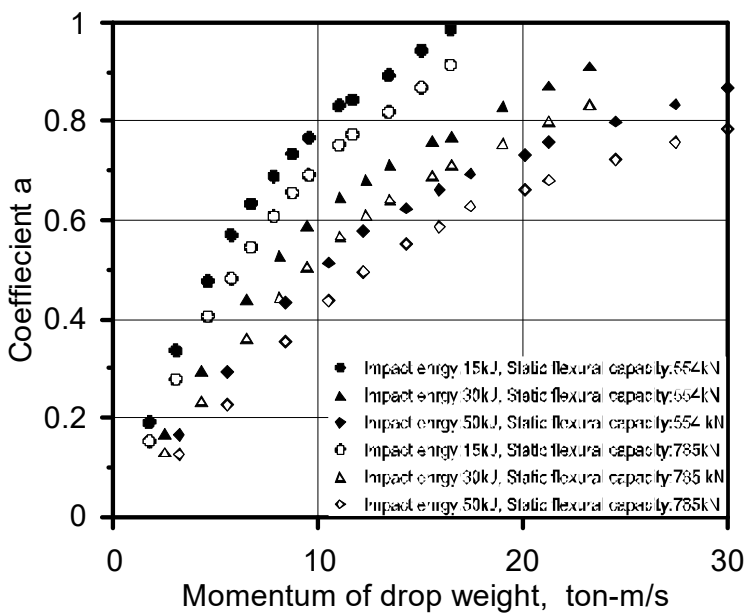

Figure 4: Coefficient alpha for momentum.

\subsection{Crack pattern}

When the momentum is large, which means that for a given value of impact energy the mass is large and the impact velocity is low, the crack pattern was similar to that of static state. Crack was generated from the bottom of the beam and propagated upward. However, in case that the momentum is small, which is equal to the case that the mass is light and the impact velocity is high, the shear plug phenomenon in which the cracks propagates downward from the collision part was remarkable. Figs 5-7 show this phenomenon well. Fig. 5(a) shows that the impact energy is $15 \mathrm{~kJ}$ at a mass is 6 ton and impact velocity is $2.24 \mathrm{~m} / \mathrm{s}$ and cracks are propagating from bottom to the top of the beam. Fig. 5(b) shows that the mass is 1.49 ton and impact velocity is $4.49 \mathrm{~m} / \mathrm{s}$ and the shear plug occurred. Fig. 6 show the case of impact energy $30 \mathrm{~kJ}$; the crack pattern is similar to that of $15 \mathrm{~kJ}$. Fig. 7 show the case of impact energy 50 
$\mathrm{kJ}$, the crack pattern of in case that the mass is 6 ton and impact velocity is $2.24 \mathrm{~m} / \mathrm{s}$ and the case that the mass is 1.49 ton and impact velocity is $4.49 \mathrm{~m} / \mathrm{s}$ is similar. However, in case that the momentum is high, a large number of cracks occur in the lower part of the beam after the shear plug occurs, but when the momentum is small, the shear plug is concentrated in the center of the beam and the number of cracks generated in the lower part is relatively small.

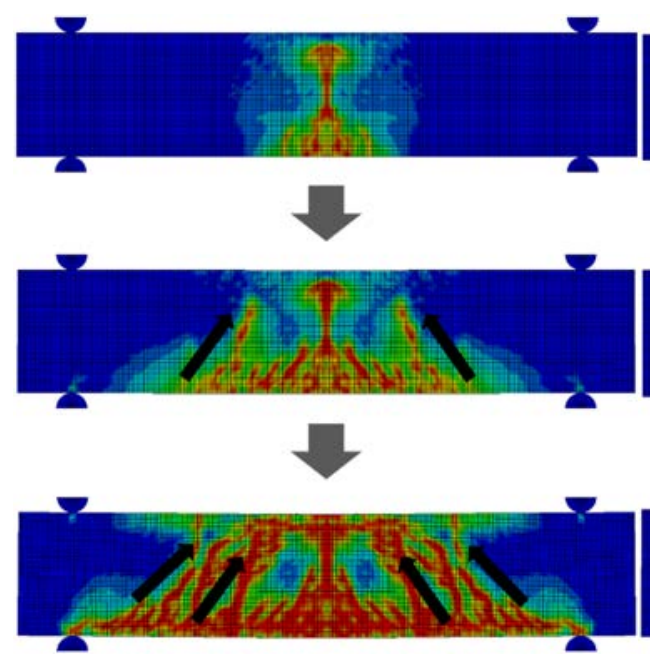

(a)
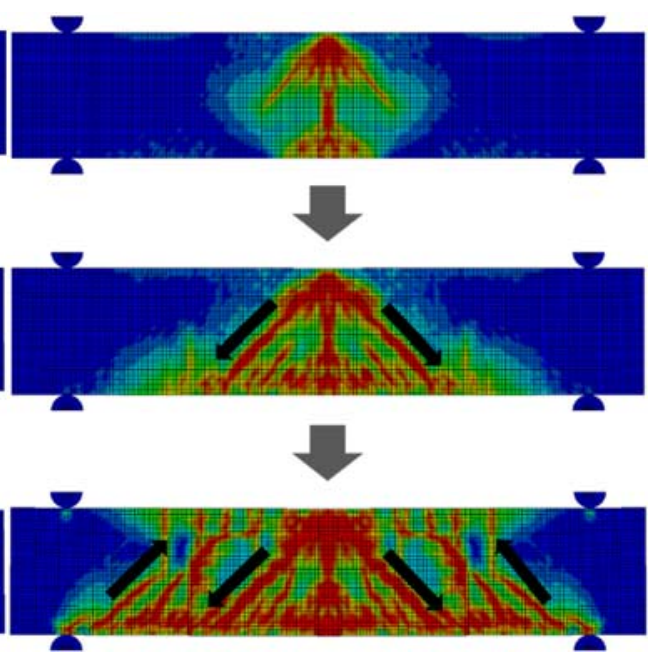

(b)

Figure 5: Impact energy $15 \mathrm{~kJ}$. (a) Crack pattern in the case that mass is 6 ton and impact velocity is $2.24 \mathrm{~m} / \mathrm{s}$; (b) Crack pattern in the case that mass is 1.49 ton and impact velocity is $4.49 \mathrm{~m} / \mathrm{s}$.

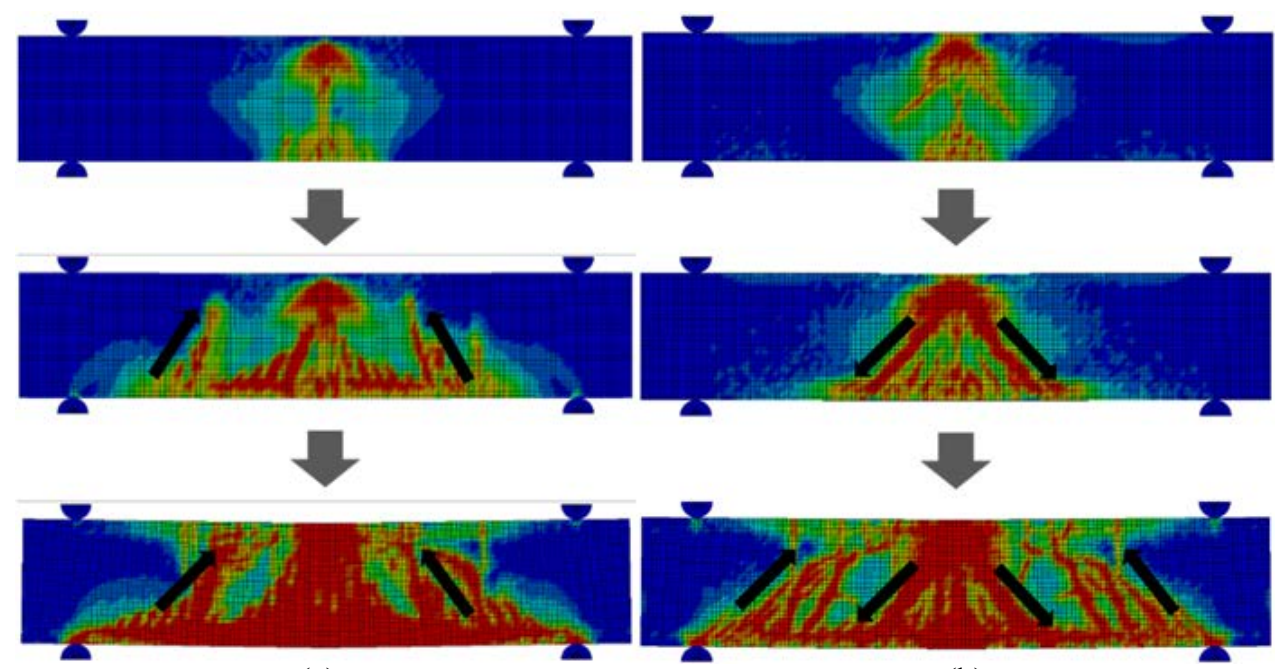

(a)

(b)

Figure 6: Impact energy $30 \mathrm{~kJ}$. (a) Crack pattern in the case that mass is 6 ton and impact velocity is $2.24 \mathrm{~m} / \mathrm{s}$; (b) Crack pattern in the case that mass is 1.49 ton and impact velocity is $4.49 \mathrm{~m} / \mathrm{s}$. 

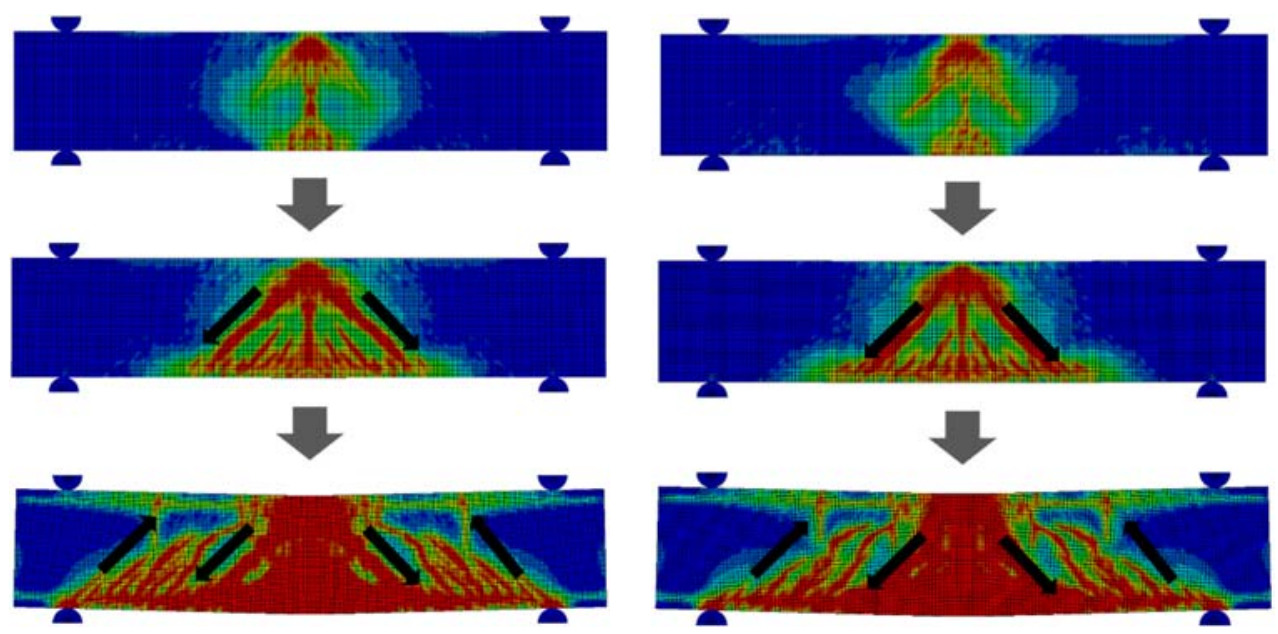

Figure 7: Impact energy $50 \mathrm{~kJ}$. (a) Crack pattern in the case that mass is 6 ton and impact velocity is $2.24 \mathrm{~m} / \mathrm{s}$; (b) Crack pattern in the case that mass is 1.49 ton and impact velocity is $4.49 \mathrm{~m} / \mathrm{s}$

\section{CONCLUSION}

In this study, the effect of the momentum of drop weight was investigated through FE analysis. From the analysis, following conclusions were derived.

- The momentum of drop weight depends on the maximum deflection. Especially, the maximum deflection was directly proportional to the momentum of the drop weight.

- It was confirmed that the coefficient alpha in the previous empirical equation was not a constant and to be a variable for momentum.

- The crack pattern differs from the static state and depends on the momentum of drop weight. Especially, if the momentum is small, which means that the impact velocity is high, shear plug phenomena was prominent.

- From the above results, the effect of the momentum of drop weight should be considered in the previous empirical equation in order to accurately evaluate the behavior of RC beam under impact loading.

- This results will be used as the basic for the modification of the previous empirical equation and it will be confirmed through the experiment at Extreme Performance Testing Center of Seoul National University.

\section{ACKNOWLEDGEMENTS}

This work was supported by the Infrastructure and Transportation Technology Advancement Research Program funded by the Ministry of Land, Infrastructure and Transport of Korean government [grant number 18CTAP-C129906-02]; the National Research Foundation of Korea (NRF) grant funded by the Korea government [grant number NRF2017R1A2B2003640].

\section{REFERENCES}

[1] Kishi, N., Nakano, O., Matsuoka, K.G. \& Ando, T., Experimental study on ultimate strength of flexural-failure-type RC Beams under impact loading. Proceedings of the 
16th International Conference on Structural Mechanics in Reactor Technology, pp. 17, 2001.

[2] Tachibana, S., Masuya, H. \& Nakamura, S., Performance based design of reinforced concrete beams under impact. Natural Hazards and Earth System Science, 10, pp. 10691078, 2010.

[3] Kishi, N. \& Mikami, H., Empirical formulas for designing reinforced concrete beams under impact loading. ACI Structural Journal, pp. 509-519, 2012.

[4] Zhan, T., Wang, Z. \& Ning, J., Failure behaviors of reinforced concrete beams subjected to high impact loading. Eng. Fail. Anal, 56, pp. 233-243, 2015.

[5] Markovich, N., Kochavi E. \& Ben-Dor, G., An improved calibration of the concrete damage model. Finite Element in Analysis and Design, 47, pp. 1280-1290, 2011. 